\title{
Monitoring Program Keluarga Harapan Berbasis Mobile GIS Menggunakan K-Means Clustering
}

Family Hope Program Monitoring Based on Mobile GIS Using K-Means Clustering

\author{
Ahmad Muhariya ${ }^{1}$, Bebas Widada $^{2}$, Sri Siswanti ${ }^{3}$ \\ ${ }^{1,3}$ Informatika, STMIK Sinar Nusantara Surakarta \\ ${ }^{2}$ Sistem Informasi, STMIK Sinar Nusantara Surakarta \\ E-mail: ${ }^{1}$ ahmadmuhariya1@gmail.com, ${ }^{2}$ bbswdd@sinus.ac.id, ${ }^{3}$ syswanty@ sinus.ac.id
}

\begin{abstract}
Abstrak
Pemerintah Indonesia sudah menyelenggarakan berbagai program bantuan sosial untuk menanggulangi kemiskinan, diantaranya adalah Program Keluarga Harapan (PKH). PKH merupakan bantuan tunai bersyarat yang diberikan kepada rumah tangga sangat miskin dimana dalam keluarga tersebut terdapat balita, anak usia SD, SMP, SMA, ibu hamil, orangtua yang sudah lanjut usia dan adanya anggota keluarga penyandang dissabilitas berat. Tingkat kemiskinan menentukan besarnya perolehan bantuan yang diterima, dimana banyaknya kategori rumah tangga sangat miskin dan juga kewajiban bagi peserta untuk tetap menjalankan komitmen di bidang kesehatan dan pendidikan merupakan parameter tingkat kemiskinan. Tujuan penelitian adalah pengembangan aplikasi monitoring $\mathrm{PKH}$ berbasis mobile GIS dengan metode k-means clustering. Hasil pengujian validitas dengan menggunakan data sampel 21, dapat disimpulkan bahwa sistem dapat mengelompokkan keluarga miskin menjadi 7 cluster dengan tingkat ketelitian 90,4\%, sehingga K-Means Clustering yang digunakan memiliki nilai akurasi tinggi untuk clustering keluarga miskin.
\end{abstract}

Kata kunci: K-Means Clsutering, Program Keluarga Harapan, Keluarga Miskin, Mobile

\begin{abstract}
The Government of Indonesia has organized various social assistance programs to overcome poverty, including the Family of Hope Program (PKH). PKH is a conditional cash assistance provided to very poor households where there are toddlers, elementary school, junior high, high school, pregnant women, elderly parents and family members with severe disabilities. The poverty level determines the amount of assistance received, where many categories of households are very poor and is also the obligation for participants to continue to carry out their commitments in the health and education sectors is a parameter of the poverty level. The purpose of the research is the development of a mobile GIS-based PKH monitoring application with a k-means clustering method. Validity test results using sample data 21, it can be concluded that the system can group poor families into 7 clusters with a precision rate of $90.4 \%$, so that the K-Means Clustering used has a high accuracy value for clustering poor families.
\end{abstract}

Keywords: K-means Clustering, Family Hope Program, Poor Families, Mobile

\section{PENDAHULUAN}

Kondisi yang berada di bawah garis suatu nilai standar kebutuhan minimum baik itu untuk makanan ataupun non makanan merupakan suatu kemiskinan. Garis kemiskinan adalah sejumlah rupiah yang diperlukan oleh individu untuk dapat membayar kebutuhan makanan setara 2100 kilo kalori per orang per hari dan kebutuhan non-makanan yang terdiri dari perumahan, pakaian, pendidikan, transportasi, serta aneka barang dan jasa lainnya [1]. Guna menanggulangi kemiskinan pemerintah Indonesia berbagai program diantaranya adalah Program Keluarga Harapan (PKH). PKH diluncurkan pertama kali oleh pemerintah pada tahun 2007 dan telah telah 
berkonstribusi dalam menekan angka kemiskinan dan mendorong kemandirian Keluarga Penerima Manfaat (PKM). PKH merupakan program bantuan sosial yang diberikan kepada keluarga miskin dan rentan. Penerima PKH sudah terdaftar dalam Data Terpadu Kesejahteraan Sosial (DTKS) dan sudah ditetapkan sebagai PKM PKH [2]. Peningkatan kondisi sosial ekomoni bagi Rumah Tangga Sangat Miskin (RTSM), peningkatan taraf pendidikan anak-anak serta peningkatan kesehatan dan status gizi bagi balita dan ibu hamil merupakan tujuan PKH. Harapan dengan adanya $\mathrm{PKH}$ adalah selain mampu menurunkan angka kemiskinan, dapat meningkatkan sumber daya manusia khusunya kelompok masyarakat miskin, akan tetapi program ini mampu memutuskan rantai kemiskinan itu sendiri. Kuota yang terbatas dalam penerimaan bantuan PKH maka perlu untuk di adakan pengclusteran di karenakan untuk memenuhi indek yang berbeda sehingga dalam menentukan proioritas semakin mudah dan akurat.

Guna menganalisa pemakaian obat pada sebuah puskesmas yaitu dengan clusterisasi menggunakan data mining. Clusterisasi digunakan untuk mengajukan permohonan obat pada periode yang akan datang. Hasil penelitian ini adalah dapat mengelompokkan tingkat pemakaian obat pada apotik puskesmas [3]. Penerapan data mining dengan algoritma K-Means Clustering dapat mengolongkan data keluarga. Penerapan Metode ini dapat menentukan keluarga mana yang dianggap kurang mampu (miskin), sederhana, dan kaya dalam membutuhkan bantuan dana dengan tingkat akurasi sebesar 69\%. Penurunan tingkat akurasi dikarenakan data total aset yang cukup bervariasi dan besar, sehingga ada keluarga yang tidak sesuai dengan kriteria golongan tersebut [4].

Clusterisasi menggunakan K-means merupakan salah satu metode data clustering nonhirarki yang mengelompokan data dalam bentuk satu atau lebih cluster/kelompok. Data yang mempunyai karakteristik sama dikelompokkan dalam satu cluster, sedang yang mempunyai karakteristik berbeda juga dikelompokkan dalam satu cluster yang lain, sehingga data yang ada di dalam satu kelompok mempunyai tingkat variasi [5]. Metoda $\mathrm{K}$-Means dapat digunakan untuk menjelaskan algorima dalam penentuan suatu objek ke dalam klaster tertentu berdasarkan rataan terdekat dan mudah diimplementasikan [6]. Data Mining untuk mengelompokkan penerima bantuan dengan menggunakan metode K-Means dalam pengklasteran penduduk miskin [7][8].

Sistem Informasi Geografis (SIG) merupakan salah satu teknologi yang membantu mengelola, menyimpan, melakukan pemrosesan, analisis dan menampilkan data terkait geografis [9]. Pada penelitian pemetaan warga miskin dengan sistem informasi geografis menggunakan Clustering K- Means, didapatkan bahwa sistem mampu mengolah data warga miskin beserta atribut dan kriteria yang dikelompokkan kedalam 3 nilai kategori, yakni Mampu, Miskin, Cukup pada setiap daerah dari beberapa warga yang digunakan untuk proses perhitungan. Sistem juga mampu menghasilkan peta per daerah yang ditandai oleh marker yang sudah ditentukan latitude dan longitude sehingga bisa sesuai dengan hasil dari proses perhitungan yang telah dikelompokkan menjadi 3 kategori [10].

Penelitian ini selain digunakan untuk mengelompokkan bantuan Program Keluarga Harapan $(\mathrm{PKH})$ juga dapat digunakan untuk memantau penyebaran program bantuan dengan menggunakan smartphone.

Perbedaan dengan penelitian sebelumnya adalah penentuan Clustering dalam 7 tingkatan kemiskinan yaitu Miskin 1 sampai 7 dan untuk monitoring bantuan PKH dapat dilakukan menggunakan Sistem Informasi Geografis berbasis mobile phone.

\section{METODE PENELITIAN}

\subsection{Pengumpulan Data}

Tahap ini dilakukan dengan cara observasi yaitu dengan cara Peneliti langsung terlibat dalam melakukan peneliatia ke instansi terdekat yaitu ke Dinas Sosial dan PKH di Kecamatan, wawancara yaitu wawancara mengenai proses penerimaan manfaat ke $\mathrm{PKH}$, aturan dan prosedur penerimaan manfaat, sedang studi pustaka dilakukan dengan mencari referensi yang berhubungan dengan penelitian terkait baik lewat internet maupun buku. 


\subsection{Metode K-Means Clustering}

Sebuah metode analisis kelompok yang mengarah pada pemartisisan $\mathrm{N}$ objek pengamat kedalam K kelompok (Cluster) dimana setiap objek pengamat memiliki sebuah kelompok dengan mean (rata-rata) terdekat.

Sehingga data berkarateristik sama dimasukkan kedalam satu kelompok yang sama dan jika data berkarateristik berbeda dikelompokkan ke dalam kelompok yang lain.

Algoritma dasar clustering dengan K-Means secara umum adalah sebagi berikut :

a. Menentukan jumlah cluster.

b. Mengalokasikan data secara random ke dalam cluster.

c. Melakukan perhitungan jarak setiap data yang ada disetiap pusat Cluster dengan rumus sebagai berikut :

$$
d_{i j}=\sqrt{\left(x_{i}-x_{j}\right)^{2}+\left(y_{i}-y_{j}\right)^{2}}
$$

d. Menentukan alokasi masing-masing data ke centroid/ rata-rata terdekat.

e. Kembali ke langkah c, jika ada data yang masih berpindah cluster

Gambar 1 adalah algoritma $K$-means clustering.

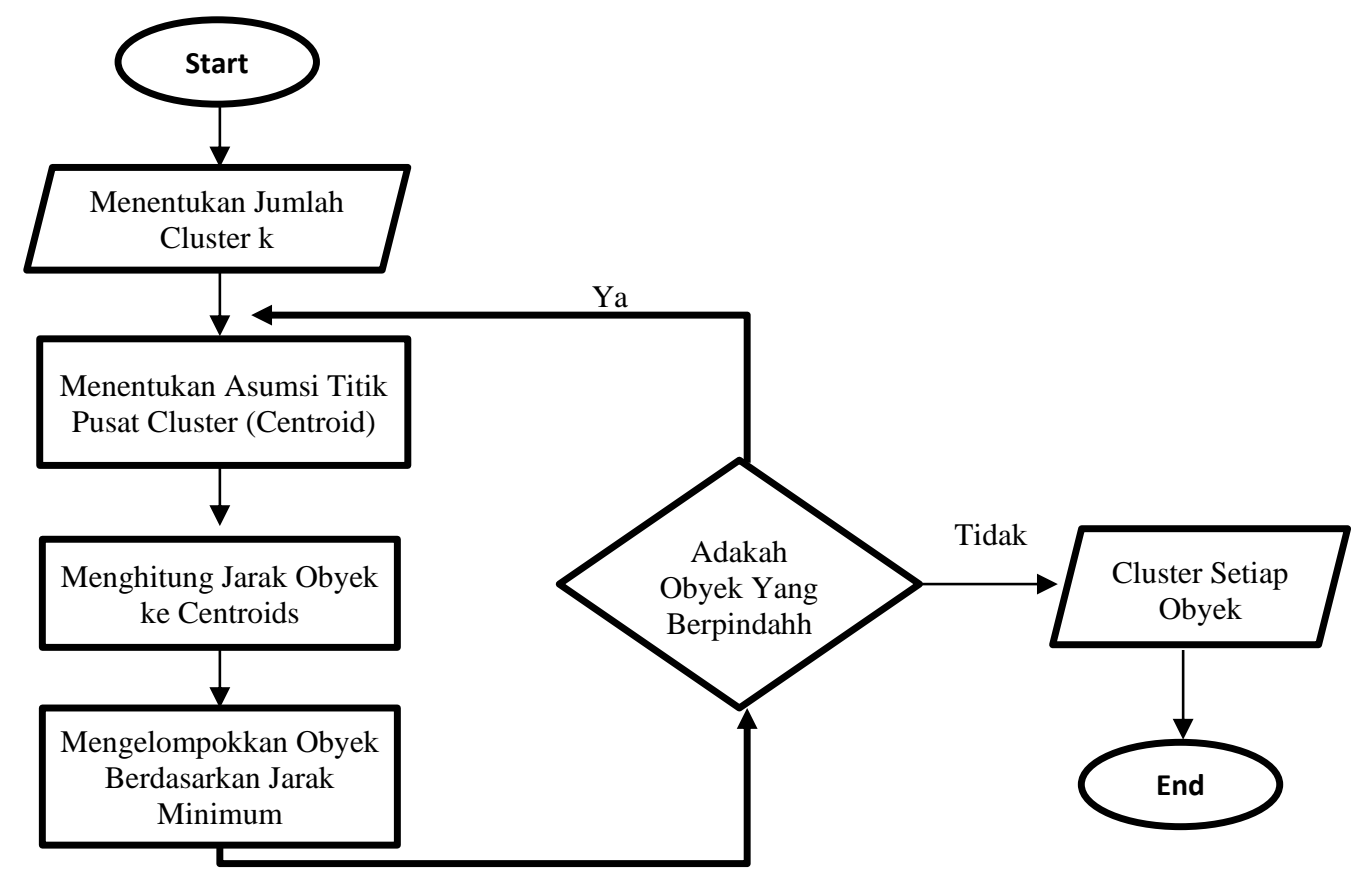

Gambar 1 Flowchart Algoritma Kmeans

\subsection{Implementasi}

Penyusunan kode program dengan menggunakan PHP. Sedangkan database disusun dengan MySQL dan server yang digunakan adalah XAMPP. Penyusunan mobilenya menggunakan bahasa pemrograman Java.

\subsection{Pengujian}

Pengujian validitas dilakukan untuk mengetahui apakah metode yang diterapkan di aplikasi yang akan dibuat sama dengan perhitungan menggunakan Microsoft Excel lalu dengan Silhouette Coefficient. 


\section{HASIL DAN PEMBAHASAN}

\subsection{Pengumpulan data PKH}

Tabel 1 merupakan Data PKH yang diambil berjumlah 21 Peserta PKH yang ada di Kecamatan Klego dengan Variabel : Anak SD, Anak SMP, Anak SMA, Ibu Hamil, Usia Dini, Lansia, Disabilitas

Tabel 1 Data PKH

\begin{tabular}{|c|c|c|c|c|c|c|c|c|}
\hline No & NAMA & SD & SMP & SMA & BUMIL & USIA DINI & LANSIA & DISABILITAS \\
\hline 1 & Calon 1 & 1 & 1 & 0 & 0 & 0 & 0 & 0 \\
\hline 2 & Calon 2 & 0 & 2 & 0 & 0 & 0 & 0 & 0 \\
\hline 3 & Calon 3 & 1 & 0 & 0 & 0 & 0 & 0 & 0 \\
\hline 4 & Calon 4 & 1 & 0 & 0 & 0 & 1 & 0 & 0 \\
\hline 5 & Calon 5 & 2 & 0 & 0 & 0 & 2 & 0 & 0 \\
\hline 6 & Calon 6 & 1 & 1 & 1 & 0 & 0 & 0 & 0 \\
\hline 7 & Calon 7 & 1 & 1 & 0 & 0 & 0 & 0 & 0 \\
\hline 8 & Calon 8 & 2 & 0 & 0 & 0 & 1 & 0 & 0 \\
\hline 9 & Calon 9 & 0 & 1 & 0 & 0 & 0 & 0 & 1 \\
\hline 10 & Calon 10 & 1 & 0 & 1 & 0 & 1 & 0 & 0 \\
\hline 11 & Calon 11 & 1 & 1 & 1 & 0 & 0 & 0 & 0 \\
\hline 12 & Calon 1 & 0 & 0 & 1 & 0 & 0 & 0 & 0 \\
\hline 13 & Calon 13 & 1 & 1 & 0 & 0 & 0 & 0 & 0 \\
\hline 14 & Calon 14 & 0 & 1 & 0 & 0 & 0 & 0 & 0 \\
\hline 15 & Calon 15 & 2 & 0 & 0 & 0 & 0 & 0 & 0 \\
\hline 16 & Calon 16 & 1 & 0 & 0 & 0 & 1 & 0 & 0 \\
\hline 17 & Calon 17 & 2 & 0 & 0 & 0 & 0 & 0 & 0 \\
\hline 18 & Calon 18 & 1 & 0 & 0 & 0 & 2 & 0 & 0 \\
\hline 19 & Calon 19 & 1 & 0 & 0 & 1 & 0 & 0 & 0 \\
\hline 20 & Calon 20 & 1 & 0 & 0 & 0 & 1 & 0 & 0 \\
\hline 21 & Calon 21 & 2 & 1 & 1 & 0 & 0 & 0 & 0 \\
\hline
\end{tabular}

Data yang digunakan untuk clustering adalah PKH di kecamatan Klego yang berjumlah 21 peserta $\mathrm{PKH}$.

Menentukan centroid awal random

$\mathrm{C} 1: 1,0,1,0,1,0,0$

$\mathrm{C} 2: 1,0,0,0,0,0,0$

$\mathrm{C} 3: 1,1,0,0,0,0,0$

$\mathrm{C} 4: 0,0,1,0,0,0,0$

C5 : $1,0,0,1,0,0,0$

C6 : 1, 0, 0, 0, 1, 0, 0

C7 : 2, 1, 1, 0, 0, 0, 0

Tabel 2 adalah hasil perhitungan jarak terpendek.

Tabel 2 Proses clustering iterasi 1

\begin{tabular}{|c|c|c|c|}
\hline NO & NAMA & Jarak Euclidean & $\begin{array}{c}\text { Hasil } \\
\text { cluster }\end{array}$ \\
\hline 1 & Calon 1 & 0 & C3 \\
\hline
\end{tabular}




\begin{tabular}{|c|c|c|c|}
\hline 2 & Calon 2 & 1,414213562 & $\mathrm{C} 3$ \\
\hline 3 & Calon 3 & 0 & $\mathrm{C} 2$ \\
\hline 4 & Calon 4 & 0 & C6 \\
\hline 5 & Calon 5 & 1,414213562 & C6 \\
\hline 6 & Calon 6 & 1 & $\mathrm{C} 3$ \\
\hline 7 & Calon 7 & 0 & $\mathrm{C} 3$ \\
\hline 8 & Calon 8 & 1 & C6 \\
\hline 9 & Calon 9 & 1,414213562 & $\mathrm{C} 3$ \\
\hline 10 & Calon 10 & 0 & $\mathrm{C} 1$ \\
\hline 11 & Calon 11 & 1 & $\mathrm{C} 3$ \\
\hline 12 & Calon 1 & 0 & $\mathrm{C} 4$ \\
\hline 13 & Calon 13 & 0 & $\mathrm{C} 3$ \\
\hline 14 & Calon 14 & 1 & $\mathrm{C} 3$ \\
\hline 15 & Calon 15 & 1 & $\mathrm{C} 2$ \\
\hline 16 & Calon 16 & 0 & C6 \\
\hline 17 & Calon 17 & 1 & $\mathrm{C} 2$ \\
\hline 18 & Calon 18 & 1 & C6 \\
\hline 19 & Calon 19 & 0 & $\mathrm{C} 5$ \\
\hline 20 & Calon 20 & 0 & C6 \\
\hline 21 & Calon 21 & 0 & $\mathrm{C} 7$ \\
\hline
\end{tabular}

Apabila masih ada perubahan pada Cluster dan obyek, maka proses akan dilakukan perulangan sampai data sudah sama atau tidak ada perubahan data.

Proses clustering penelitian yang sudah di hitung manual, dan perulangan yang di lakukan sampai iterasi yang ke 3 sehingga hasil seperti yang di tunjukan pada Tabel 3 .

Tabel 3 Proses Clustering iterasi 3

\begin{tabular}{|c|c|c|c|}
\hline NO & NAMA & Jarak Euclidean & $\begin{array}{c}\text { Hasil } \\
\text { cluster }\end{array}$ \\
\hline 1 & Calon 1 & 0,484122918 & C3 \\
\hline 2 & Calon 2 & 1,111024302 & C3 \\
\hline 3 & Calon 3 & 0,666666667 & C2 \\
\hline 4 & Calon 4 & 0,471404521 & C6 \\
\hline 5 & Calon 5 & 0,942809042 & C6 \\
\hline 6 & Calon 6 & 0,856956825 & C3 \\
\hline 7 & Calon 7 & 0,484122918 & C3 \\
\hline 8 & Calon 8 & 0,745355992 & C6 \\
\hline 9 & Calon 9 & 1,111024302 & C3 \\
\hline 10 & Calon 10 & 0 & C1 \\
\hline 11 & Calon 11 & 0,856956825 & C3 \\
\hline 12 & Calon 1 & 0 & C4 \\
\hline 13 & Calon 13 & 0,484122918 & C3 \\
\hline 14 & Calon 14 & 0,695970545 & C3 \\
\hline 15 & Calon 15 & 0,333333333 & C2 \\
\hline 16 & Calon 16 & 0,471404521 & C6 \\
\hline 17 & Calon 17 & 0,333333333 & C2 \\
\hline 18 & Calon 18 & 0,745355992 & C6 \\
\hline & & & \\
\hline
\end{tabular}




\begin{tabular}{|l|c|c|c|}
\hline 19 & Calon 19 & 0 & C5 \\
\hline 20 & Calon 20 & 0,471404521 & C6 \\
\hline 21 & Calon 21 & 0 & C7 \\
\hline
\end{tabular}

Berdasarkan hasil K-Means clustering tersebut dapat disimpulkan :

- cluster pertama, ada 1 data : data ke- 10.

- cluster kedua, ada 3 data: data ke- 3, 15, 17.

- cluster ketiga, ada 8 data : data ke-1, 2, 6, 7, 9, 11, 13, 14.

- cluster keempat, ada 1 data : data ke- 12 .

- cluster kelima, ada 1 data : data ke- 19.

- cluster keenam, ada 6 data : data ke- 4, 5, 8, 16, 18, 20.

- cluster ketujuh, ada 1 data: data ke- 21.

\subsection{Implementasi sistem}

Menu utama pada Gambar 2 terdiri dari input data KPM, Pengelolaan data KPM, hasil clustering berupa informasi lokasi penerima manfaat, tombol bantuan untuk membantu penggunaan aplikasi.

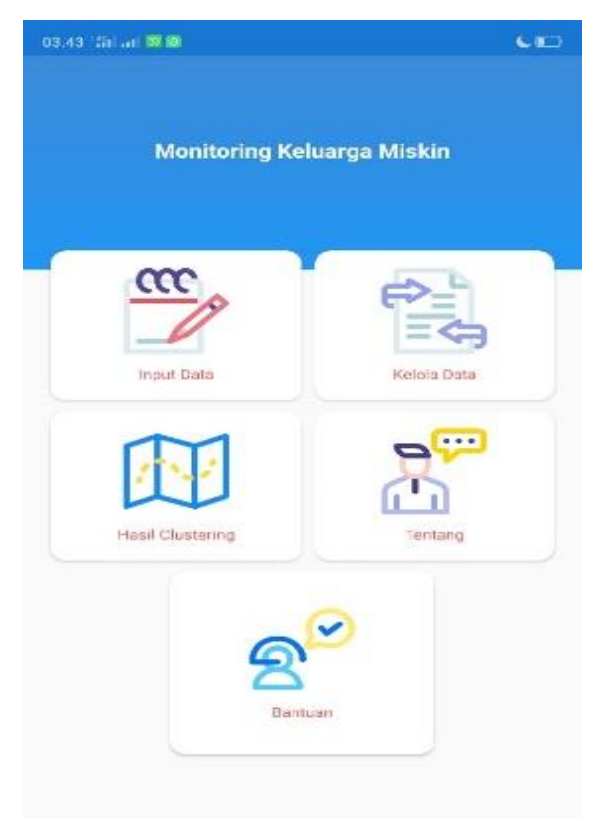

Gambar 2 Tampilan Halaman utama

Gambar 3 merupakan halaman untuk input data KPM, data yang di inputkan adalah Nama Penerima, jumlah pendidikan anak mulai SD, SMP dan SMA, Jumlah Ibu Hamil, Jumlah Usia Dini, Jumlah Lansia, Jumlah Disabilitas dan Koordinat pada alamat tersebut. Selain untuk input data di form ini juga terdapat fasilitas untuk melakukan perbaikan data atau penghapusan data. 


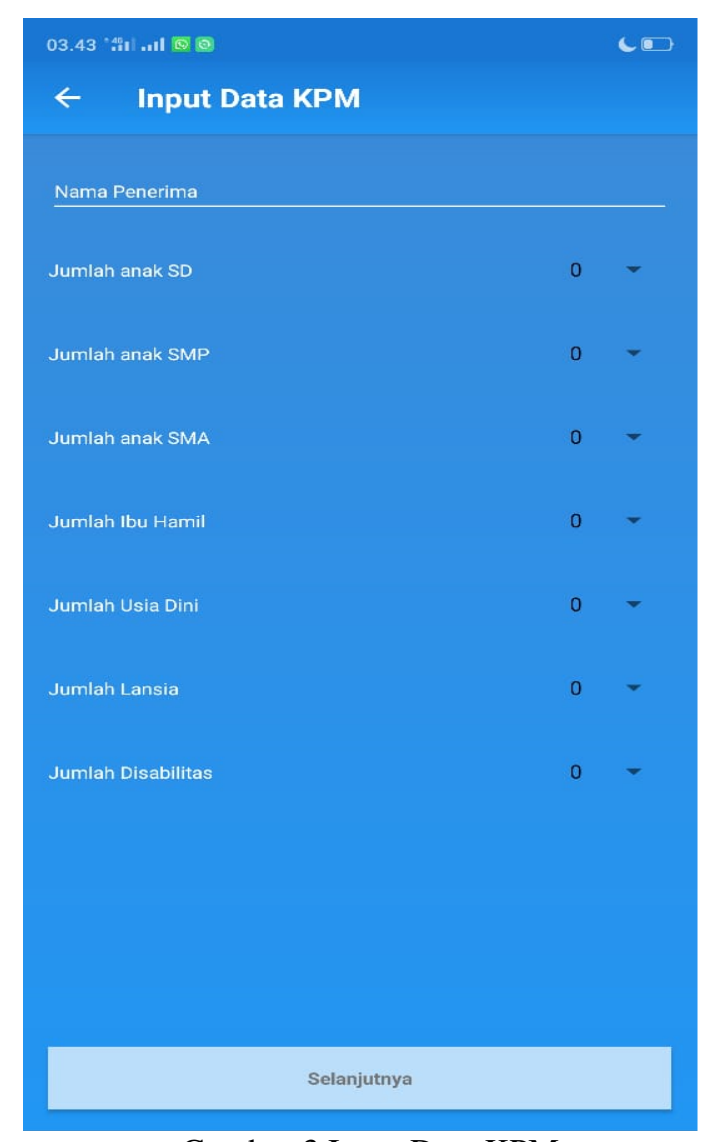

Gambar 3 Input Data KPM

Gambar 4 merupakan halaman hasil, dimana di goole maps akan di tampilkan informasi lokasi rumah keluarga penerima manfaat dalam bentuk marker. Setelah user mengaktifkan GPS di smartphone, user dapat memlih marker, maka user akan mendapatkan informasi rute ke lokasi tujuan.

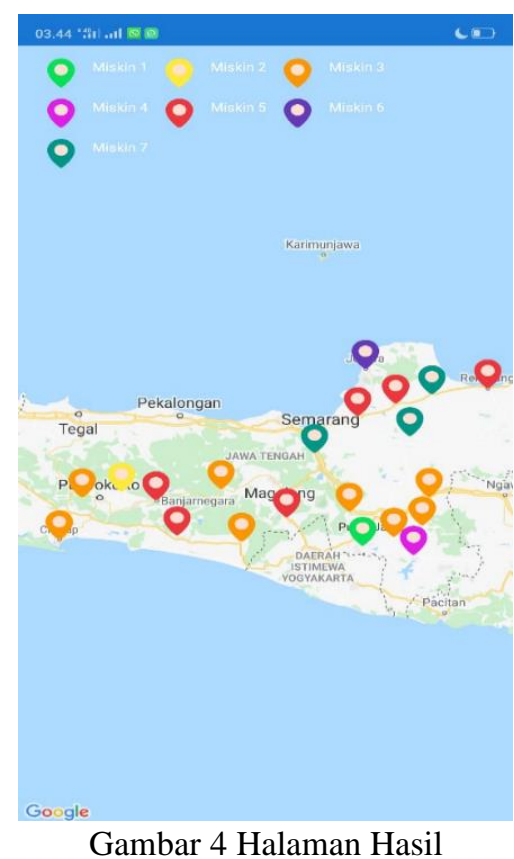




\subsection{Pengujian Validitas}

Pengujian ini diperoleh dengan membandingkan hasil perhitungan di aplikasi clustering PKH dengan hasil perhitungan manual. Dalam perhitungan jumlah data sampel 21 kemudian menghasilkan 3 iterasi dengan jumlah data perhitungan 63. Dari data tersebut terdapat 6 data dari 63 yang mengalami perbedaan pada perhitungan excel dengan perhitungan aplikasi lalu dengan Silhouette Coefficient. Berikut perbedaan dalam perbandingan perhitungan excel dengan aplikasi setiap iterasi bisa di lihat pada Tabel 4.

Tabel 4 Uji Validitas penghitungan excel dengan aplikasi

\begin{tabular}{|c|c|c|c|}
\hline Iterasi & Nama & $\begin{array}{c}\text { Perhitungan } \\
\text { excel }\end{array}$ & $\begin{array}{c}\text { Perhitungan Aplikasi K- } \\
\text { Means }\end{array}$ \\
\hline 1 & Calon 6 & C3 & C7 \\
\hline 1 & Calon 11i & C3 & C7 \\
\hline 2 & Calon 6 & C3 & C7 \\
\hline 2 & Calon 11i & C3 & C7 \\
\hline 3 & Calon 6 & C3 & C7 \\
\hline 3 & Calon 11i & C3 & C7 \\
\hline
\end{tabular}
diperoleh :

Berdasarkan tabel diatas dengan pengujian validitas yang telah dilakukan sehingga

$$
\begin{aligned}
\text { Kinerja Sistem } & =\frac{\text { banyaknya hasil pengujian bernilai benar }}{\text { banyaknya data }} \times 100 \% \\
& =\frac{57}{63} \times 100 \%=90,4 \%
\end{aligned}
$$

Dari hasil diatas diperoleh tingkat akurasi pemetaan sebesar 90,4\%, sehingga pemanfaatan metode $K$-means clustering untuk pengelompokan program bantuan memiliki akurasi yang tinggi.

Pengujian kualitas dan kekuatan Cluster menggunakan Silhouette Coefficient. Pada Tabel 5 dapat dilihat nilai SC nya, dimana nilai $\mathrm{SC} 0 \leq \mathrm{SC} \leq 1$, semakin besar nilai SC maka kualitas cluster semakin baik.

Tabel 5 Hasil Pengujian Validitas dengan Silhouette Coefficient

\begin{tabular}{|c|c|c|c|}
\hline $\mathbf{l}$ & $\mathbf{a ( i )}$ & $\mathbf{b}(\mathbf{i})$ & $\mathbf{S}(\mathbf{i})$ \\
\hline 1 & 0,832632446 & 1,598554237 & 0,479134 \\
\hline 2 & 1,445850838 & 2,65279168 & 0,45497 \\
\hline 3 & 1 & 1,432879346 & 0,302105 \\
\hline 4 & 0,682842712 & 1,590864956 & 0,570773 \\
\hline 5 & 1,248528137 & 2,54222996 & 0,508885 \\
\hline 6 & 1,125473597 & 1,748475891 & 0,356312 \\
\hline 7 & 0,832632446 & 1,598554237 & 0,479134 \\
\hline 8 & 1,082842712 & 1,868894131 & 0,420597 \\
\hline 9 & 1,445850838 & 2,269416854 & 0,362898 \\
\hline 10 & 1,56435432 & 1,611175356 & 0,02906 \\
\hline 11 & 1,125473597 & 1,748475891 & 0,356312 \\
\hline 12 & 1 & 1,748475891 & 0,356312 \\
\hline 13 & 0,832632446 & 1,598554237 & 0,479134 \\
\hline
\end{tabular}




\begin{tabular}{|c|c|c|c|}
\hline 14 & 1,118346732 & 2,027985675 & 0,448543 \\
\hline 15 & 0,5 & 1,749776762 & 0,714249 \\
\hline 16 & 0,682842712 & 1,590864956 & 0,570773 \\
\hline 17 & 0,5 & 1,749776762 & 0,714249 \\
\hline 18 & 1,082842712 & 2,328005535 & 0,534862 \\
\hline 19 & 1,414213562 & 1,69205304 & 0,164203 \\
\hline 20 & 0,682842712 & 1,590864956 & 0,570773 \\
\hline 21 & 1,567854 & 1,836678836 & 0,146365 \\
\hline & & Rata-rata & $\mathbf{0 , 4 2 9 5 0 7}$ \\
\cline { 3 - 4 } & & &
\end{tabular}

Dari hasil pengujian silhouette coefficient yang telah dipaparkan pada tabel 5 Menghasilkan nilai SC rata rata sebesar 0,429507 yang menandakan pengelompokan tersebut masuk pada kategori weak structure.

\section{KESIMPULAN DAN SARAN}

Terciptanya aplikasi untuk memonitoring PKH dengan k-means clustering berbasis mobile, sehingga aplikasi ini dapat diakses dimanapun. Hasil pengujian validitas dengan menggunakan data sampel 21, adalah sistem ini dapat mengelompokkan PKH dalam 7 Cluster dimana tingkat ketelitian sebesar 90,4\%. Sehingga metode pemanfaatan metode K-Means Clustering untuk pengelompokan program bantuan bagi PKH memiliki nilai akurasi tinggi.

Pengembangan sistem dengan penambahan beberapa fitur seperti pencarian pada peta hasil kluster hingga dapat diketahui PKH mana yang masuk dalam karateristik..

\section{DAFTAR PUSTAKA}

[1] Badan Pusat Statistik, "Profil Kemiskinan Di Indonesia Maret 2017," Badan Pusat Statistik, no. 66, pp. 1-8, 2017.

[2] Kementerian Sosial Republik Indonesia, "Panduan pelaksanaan PKH 2020.” pp. 3-14, 2020.

[3] T. Taslim and F. Fajrizal, "Penerapan algorithma k-mean untuk clustering data obat pada puskesmas rumbai," Digit. Zo. J. Teknol. Inf. dan Komun., vol. 7, no. 2, pp. 108-114, 2016, doi: 10.31849/digitalzone.v7i2.602.

[4] Eric Fammaldo dan Lukman Hakim, "Penerapan Algoritma K-Means Clustering Untuk Pengelompokan Tingkat Kesejahteraan Keluarga Untuk Program Kartu Indonesia Pintar," J. Ilm. Teknol. Inf. Terap., vol. V, no. 1, pp. 24-32, 2018.

[5] N. Sakinah, E. Buulolo, and N. Sitompul, "Kelayakan Keluarga Penerima Raskin ( Studi Kasus : Kantor Kelurahan Bantan Timur )," vol. 7, pp. 313-318, 2019.

[6] Soemartini and E. Supartini, "Analisis K-Means Cluster Untuk Pengelompokan Kabupaten / Kota Di Jawabarat Berdasarkan Indikator Masyarakat," in Konferensi Nasional Penelitian Matematika dan Pembelajarannya II (KNPMP II) Universitas Muhammadiyah Surakarta, 2017, pp. 144-154.

[7] K. dan P. A. J. Dina Sunia, "Penerapan Data Mining untuk Clustering Data Penduduk Miskin Menggunakan Algoritma K-Means," J. Ilm. Mhs. Tek. Inform., vol. Vol 1 No 2, no. 2016, pp. 121-134, 2019.

[8] M. Nanda Variestha Waworuntu and M. F. Amin, "Penerapan Metode K-Means Pemetaan Calon Penerima JAMKESDA,” Kumpilan J. Ilmu Komput., vol. 05, no. 02, pp. 190-200, 2018, [Online]. Available: http://klik.ulm.ac.id/index.php/klik/article/view/157 (05 Juni 2020).

[9] R. Wahyudi and T. Astuti, "Sistem Informasi Geografis (Sig) Pemetaan Bencana Alam Kabupaten Banyumas Berbasis Web,” J. Teknol. dan Inf., vol. 9, no. 1, pp. 55-65, 2019, 
doi: 10.34010/jati.v9i1.1448.

[10] U. Setyawan, A. Haryoko, and A. Arifia, "Sistem Informasi Geografis Pemetaan Warga Miskin Yang Pantas Mendapat Bantuan Menggunakan Metode Clustering K-Means," no. September, pp. 4-6, 2018. 